\title{
Crítica ao otimismo da vontade de transformação no contexto da pandemia: dois desafios teóricos
}

\author{
Criticism of the optimism of the will to transformation in the context of the \\ pandemic: two theoretical challenges
}

\section{Jorge Luiz Viesenteiner}

\begin{abstract}
Resumo: 0 objetivo do artigo é questionar o otimismo em relação aos anseios por transformação para algo melhor no contexto pós-pandemia. Por um lado, se é natural que desejemos alguma transformação depois da vivência do flagelo da pandemia - respostas ao sentido do sofrimento como mais um desdobramento dos ideais ascéticos, como escreveu Nietzsche -, por outro lado, o anseio por transformação encontra um limite tanto no sentido do desafio da transformação - um obstáculo para ela mesma -, quanto pelo otimismo nas teses esclarecidas que superestimam os indivíduos e seus potenciais cognitivos e subestimam o potencial dos conflitos internos. Finalizo com uma breve indicação da urgência de um programa genealógico da cultura brasileira.

Palavras-chave: Pandemia; Ideal ascético; Transformação; Aufklärung; Genealogia
\end{abstract}

Abstract: The aim of the article is to question optimism regarding the desire for transformation to something better in the post-pandemic context. On the one hand, if it is natural that we desire some transformation after experiencing the scourge of the pandemic responses to the sense of suffering as another unfolding of ascetic ideals, as Nietzsche wrote -, on the other hand, the yearning for transformation finds a limit both in the sense of the challenge of transformation - an obstacle for itself - and by optimism in the enlightened theses that overestimate individuals and their cognitive potentials and underestimate the potential of internal conflicts. I conclude with a brief indication of the urgency of a genealogical program of Brazilian culture.

Key-words: Pandemic; Ascetic ideal; Transformation; Aufklärung; Genealogy

\section{Introdução}

Os anseios humanos sobre o que poderemos aprender com a pandemia, o quanto vamos conseguir nos transformar pessoal e culturalmente, as esperanças otimistas por mais solidariedade em função da nossa fragilidade nesse momento, se estaremos melhores depois do que conseguirmos aprender com a pandemia, enfim, são temas e questões que pulularam e ainda estão presentes em jornais, revistas especializadas e nas nossas conversas informais com amigos e familiares. $\mathrm{O}$ aterrorizante número de mortos se acumula no Brasil e no mundo, e o temor diante disso nos faz projetar esperanças de algo melhor no futuro. É natural que assim o desejemos. Esse otimismo, contudo, esbarra em dois aspectos teóricos que subjazem ao anseio por uma transformação consistente, e aos quais gostaria de chamar atenção nesse texto: por um lado, no limite daquilo mesmo que denominamos de transformação, sobretudo seu alcance e fronteiras e, por outro lado, no ceticismo que nutro com a tese esclarecida que aí é pressuposta, segundo a qual se superestima as potencialidades do indivíduo, notadamente as cognitivas, e se subestimam os conflitos internos de um determinado contexto. Quaisquer expectativas de transformação para melhor por meio da vivência do flagelo da pandemia esbarram nesses dois limites. De maneira plausível, podemos denominar ambos os limites como entraves que podem ser objeto de investigação em um programa genealógico, nesse

* Professor do Departamento e da Pós-graduação em Filosofia da Universidade Federal do Espírito Santo, Vitória, ES. Email: jvies@uol.com.br ORCID: https://orcid.org/0000-0003-3727-7890 
caso, da cultura brasileira. Enfrentá-los não significa sucumbir ao pessimismo, mas levar a termo a virtude da suspeita até os patamares da crítica consistente que nos salvaguarda da autoilusão.

\section{0 anseio humano por sentido ao sofrimento e à transformação}

0 contexto da pandemia talvez exprima com mais robustez o significado original da

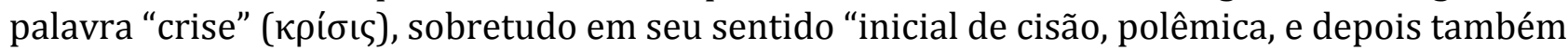
de decisão que finaliza um conflito, um juízo e uma avaliação" 1. Uma crise não implica apenas em resolvê-la decidindo por alternativas que se apresentam a nós, como se pudéssemos optar por X ou Y em função da sistematização teórica sobre a melhor alternativa, mas carrega uma componente existencial que talvez motive uma autêntica 'de-cisão' sobre algo. A crise nos arremessa ali onde justamente as alternativas fáceis nos faltam, ali onde esvazia nossa segurança e onde vacila nosso otimismo exagerado na racionalidade humana: diante da krisis, não temos controle algum. Decisão, nesse caso, pressupõe precisamente estar diante de algo que nos é fugidio, indeterminado e imprevisível - krisis/cisão -, de modo a não mais decidirmos entre alternativas, mas reconhecer o inevitável ${ }^{2}$. A componente existencial da krisis tem talvez seu correlato na angústia, e seu peso sobre nós se exprime por meio da tentativa em sistematizar algo que não pode ser sistematizado, pois tão logo se sistematize, deixa de ser krisis e se transforma em conceito, linguagem, superficializando o que nem de longe está na superfície. Krisis tem com a noção de pathos uma relação de interdependência: diante dela, é natural que soframos, mas é parte do processo humano também querer um sentido para esse sofrimento. 0 mal-estar com a pandemia talvez possa ser colocado nesses termos, principalmente para entender que alternativas ligeiras são limitadas, bem como que conjugamos o paradoxo de vivenciar o flagelo do sofrimento simultaneamente à sua expectativa de superação e seu respectivo otimismo para algo melhor.

As distintas respostas que a cultura oferece a essa componente existencial da krisis foi investigado por Nietzsche em Para genealogia da moral, ali onde se debate "O que significam ideais ascéticos". As diversas respostas ao assim chamado drama do destino da alma são tentativas não de eliminar o sofrimento, mas de dar a ele um sentido, livrando-nos, escreve Nietzsche, do "niilismo suicida":

Justamente isso significa o ideal ascético: que faltava algo, que havia uma enorme lacuna em torno do homem -, ele não sabia justificar, explicar e afirmar para si mesmo, ele sofria com o problema do seu sentido. [...] mas o sofrimento mesmo não era seu maior problema, e sim que faltava resposta para o clamor da pergunta "para quê sofrer?" [...] - e o ideal ascético lhe ofereceu um sentido ${ }^{3}$.

A somatória das respostas ao 'horror vacui' compõem então o quadro cultural com o qual nos conformamos de alguma maneira. Nesse caso, o anseio humano por um sentido do sofrer na pandemia ainda é parte do mesmo desdobramento cultural que se configura sob a forma de ideais ascéticos, independente do juízo que façamos sobre esse sentido. Em termos culturais, o significado de tais respostas é dado apenas retrospectivamente, mesmo porque no instante mesmo em que vivenciamos algo, assim escreve Nietzsche também em sua A gaia ciência, não conseguimos tomar consciência da totalidade mesma daquilo que vivenciamos ${ }^{4}$.

\footnotetext{
${ }^{1}$ KOSELLECK, Krisis, p. 1235.

2 SOOVÄLI, Entscheidung als Häresie, p. 60.

${ }^{3}$ NIETZSCHE, Para genealogia da moral (GM), Sämtliche Werke. Kritische Studienausgabe, (GM III 28).

${ }^{4}$ NIETZSCHE, A gaia ciência (GC), Sämtliche Werke. Kritische Studienausgabe, (GC 317).
} 
Qualquer resposta ou formulação de sentido ao sofrimento já é melhor do que nenhuma, e assim se explica a enigmática e paradoxal frase de Para genealogia da moral, a saber, que "o homem ainda preferirá querer o nada, a nada querer..." 5. De qualquer modo, respostas ao sentido do sofrimento - tal como essas que nos deparamos na pandemia - ainda são herdeiras e mais uma configuração dos ideais ascéticos. Enquanto tais, devem ser sempre suspeitas, apesar de inevitáveis. Também entre os gregos, porém, explicações sobre quadros de flagelo e seu respectivo sentido estiveram na agenda de discussão. Esse é o caso, dentre outros tantos, de Ésquilo e seu Prometeu acorrentado. 0 fogo roubado dos deuses e entregue aos homens é o meio pelo qual encontramos de mitigar a dor e a resposta como 'ideal ascético' à condição humana, ao mesmo tempo em que, conforme interpreta W. Jaeger, exprime a totalidade da audácia espiritual do homem, na medida em que passamos a imprimir um horizonte maior de sentido para o que fazemos. Prometeu torturado exprime a paradoxal condição humana da dor e do controle sobre ela, ou ainda, a tese de que somente "pelo caminho da dor se chega ao mais elevado conhecimento", ou se passa a ter um controle sobre sua própria situação caótica6. Em outros termos, por meio de Prometeu, Jaeger formula o germe do otimismo exagerado nas potencialidades humanas, sobretudo ao construir a ponte entre sofrimento e sentido, entre dor e sua condução à sabedoria, em suma, a capacidade de sistematizar a condição de penúria humana em torno de um horizonte maior de transformação, nesse caso, para melhor:

Prometeu é o espírito criador da cultura, que penetra e conhece o mundo, que o põe a serviço da sua vontade por meio da organização das forças dele de acordo com os seus fins pessoais, que lhe descobre os tesouros e assenta em bases seguras a vida débil e oscilante do $\mathrm{Homem}^{7}$.

As variáveis da equação existencial na pandemia são compostas, então, pela ideia de que conseguimos de alguma maneira atravessar a dor para, enfim, atingirmos um conhecimento maior das coisas, ou seja, a equação que conjuga penúria e horizontes maiores de sentido ou a transformação depois do flagelo.

Isso significa que constitui o humano não apenas o anseio, mas a efetiva capacidade de racionalizar afetos e perspectivas em um quadro maior de objetivos a serem atingidos, e justamente esse quadro geral é que pode justificar, em termos filosóficos, nosso anseio em querer nos transformarmos para 'melhor' após a pandemia. Na filosofia poderíamos denominar esse quadro geral, grosso modo, de perfeccionismo, especialmente quando ansiamos por algo que implica a travessia por um sofrimento, até ao ponto de atingirmos algum fim em que nos transformamos. Conforme venho definindo nas minhas pesquisas, juízos de caráter perfeccionista são provisórios e fluidos e, a meu ver, podem prescindir de uma teleologia inflacionada assim como de uma concepção forte de natureza humana, em proveito da habilidade em reajustarmos e reorientarmos o endosso afirmativo de um objetivo, conforme se alterem as circunstâncias sobre as quais agimos, bem como do aspecto formal e não substantivo da dinâmica de perseguição do repertório de objetivos ${ }^{8}$. Trata-se então de nos atentarmos mais ao horizonte processual na perseguição de um fim, e menos a uma meta pré-estabelecida que objetivamos atingir posteriormente. Nos juízos de perfecção, nosso horizonte ético se movimenta na medida em que também nos movimentamos.

Quero enfatizar aqui que não se trata de negar que somos capazes de racionalizar afetos com vistas a um horizonte maior de perfecção, vislumbrando que seja possível nos transformarmos em algo melhores do que já vivemos, mas apenas questionar os limites desse pendor humano. Em todas as épocas, inclusive, se quis melhorar o homem, e por diversas

\footnotetext{
${ }^{5}$ NIETZSCHE, Para genealogia da moral (GM), Sämtliche Werke. Kritische Studienausgabe, (GM III 28).

${ }^{6}$ JAEGER, Paideia: a formação do homem grego, p. 313.

7 JAEGER, Paideia: a formação do homem grego, p. 309.

8 VIESENTEINER, Considerações sobre juízos práticos perfeccionistas, no prelo.
} 
vezes isso aconteceu com considerável dose de violência instrumentalizadas tanto como violência sobre si mesmo, ou como violência institucional. Nesse ponto, Nietzsche foi cético, mais uma vez, em relação a todo tipo de moral do 'melhoramento' do homem, tal como registrou em seu Crepúsculo dos ídolos, especialmente no capítulo "Os melhoradores da humanidade". Portanto, não está em questão aqui questionar se afetos e perspectivas podem ser racionalizados com vistas a algo melhor, no sentido da construção de um juízo de caráter perfeccionista, mas pôr em questão o alcance de uma efetiva transformação para melhor. Questionar esses limites talvez nos auxilie a evitar o autoengano, tão logo nos cerramos no interior dos próprios horizontes que projetamos para além de nós. Particularmente, partilho da possibilidade da autossuperação por meio de juízos práticos de caráter perfeccionista, porém, não sem suspeitar precisamente dos nossos estreitos horizontes, cujas respostas podem se revelar meros autoenganos!

\section{Dois limites à transformação}

O primeiro limite se refere ao otimismo com o conceito mesmo de transformação, tão logo nos perguntamos se estamos falando aqui de algo que efetivamente se altera ou apenas reproduz alguns comprometimentos teóricos e morais de uma maneira nova. Cada um de nós está sempre inserido em uma situação, cujo espaço é culturalmente estruturado e informa nossa performance moral nesse espaço. Como sabemos, incorporamos afetivamente as principais estimativas de valor de uma situação, até se tornarem crenças cristalizadas ou pontos cegos, ou seja, estimativas de valor que não conseguimos problematizar, mas que atuam sobre nós na reinformação e estruturação da nossa performance moral. Em função desses comprometimentos, não enxergamos nada além da própria "perspectiva" bem como não conseguimos problematizá-la, para empregar também uma expressão cara a Nietzsche no aforismo 374 d'A gaia ciência. (A maneira como cremos e compartilhamos fake news, p.ex., remonta à nossa incorporação afetiva de uma estrutura axiológica, por meio da qual assentimos ou não conforme nosso sentimento de inclinação para tal - movimento-me aqui, como se vê, na seara da estreita conexão entre posições não-cognitivas de Hume e Nietzsche. Mesmo o insistente negacionismo da pandemia pode ser explicado, em parte, pelo assentimento afetivo às posições bolsonaristas, mesmo que evidências científicas ou o empilhamento de corpos insistam em confrontá-las). Cada anseio por transformação sob a forma de programas propositivos para algo melhor traz consigo, inevitavelmente, esses mesmos comprometimentos que atuam e estruturam novamente nossa performance, mesmo que sob outra forma. 0 que acontece quando essa dinâmica é posta em marcha, é apenas uma reprodução de performances distinta da anterior, em função da atuação dos nossos comprometimentos epistemológicos, morais, enfim, comprometimentos culturais sedimentados como ponto cegos. Não há aí qualquer genuína transformação, mas apenas mudança de condições que se nutrem dos mesmos pontos cegos. É como se tomássemos em mãos uma esfera de vidro, digamos, com uma cidade X em seu interior. Giramos a esfera em várias direções apontando para posições sempre novas, de modo que os pontos da cidade estão sempre em uma localidade distinta da anterior, e seus habitantes têm a impressão de visualizar continuamente uma nova paisagem. Para o habitante da cidade vizinha Y que observa $\mathrm{X}$ de um ponto externo, as condições mesmas da estrutura interna da cidade que informam as perspectivas, contudo, permanecem iguais. Seria preciso uma alternância de perspectivas - uma perspectividade ${ }^{9}$, como o denomino - para que o habitante da cidade $\mathrm{X}$ pudesse enxergar seus pontos cegos, por meio do habitante da cidade $\mathrm{Y}$. $\mathrm{O}$ habitante $\mathrm{X}$ não

\footnotetext{
9 Por perspectividade compreendo o movimento teórico de alternância de perspectivas. 0 termo é empregado principalmente para distinguir da noção nietzscheana de 'perspectivismo'. Perspectividade é um duplo movimento de observação e auto-observação, de maneira autorreferencial: observo uma determinada situação, mas também me auto-observo por meio da situação observada.
} 
observaria apenas $\mathrm{Y}$, mas por meio da posição de $\mathrm{Y}$ poderia também se auto-observar. Estamos então diante de dois problemas relativo ao limite da autêntica transformação: por um lado, sucumbirmos ao autoengano na medida em que nos encerramos na estreiteza dos próprios horizontes - a crítica interna - e, por outro lado, na perda da condição normativa quando alguém observa externamente os pontos cegos de outra situação, que por sua vez, é inacessível e até incompreensível para ele - a crítica externa ${ }^{10}$. Estamos falando aqui do estatuto teórico da própria crítica, que tem com a transformação uma relação de interdependência. A autêntica transformação, nesse caso, vai depender da maneira como conjugamos os vetores internos e externos da crítica, bem como na capacidade de distanciamento e autodistanciamento que estabelecemos tanto da situação em que atuamos, quanto de nós mesmos por meio de outras perspectivas ${ }^{11}$. Em qualquer situação, o potencial crítico é o impulso decisivo à transformação. 0 anseio por uma transformação para melhor pode se revelar ou um autoengano - na medida em que reproduzimos de maneira distinta os mesmos pontos cegos de sempre - ou sem qualquer força normativa - na medida em que importamos de um ponto externo soluções rápidas e intelectualistas inacessíveis a nós. Esse movimento não me parece nada óbvio como possibilidade, mas qualquer anseio de mudança para melhor em um mundo pós-pandemia pressupõe lidar com o limite e o alcance daquilo que denominamos de transformação. Esse limite, além disso, é um claro desafio aos programas genealógicos críticos.

A maneira bem-sucedida de lidarmos com o desafio crítico da autêntica transformação, exige o crescente potencial de racionalização das situações envolvidas e, com isso, chego no segundo problema em torno dos limites da transformação: o otimismo na tese esclarecida que superestima o indivíduo e subestima os conflitos internos. Ambos limites não estão em relação de antagonismo, mas são complementares.

Ao me referir a tese esclarecida, chamo atenção a um recorte específico do horizonte da Aufklärung, que é o otimismo exagerado nas potencialidades cognitivas humanas, sobretudo sua capacidade de autogoverno e autodeterminação em função da confiança na racionalidade, que pressupõe sermos capazes de sistematizar contextos pessoais e sociais, e autolegislar na vida prática. Subjaz aí então o otimismo com a racionalidade e, portanto, a consequente superestimação do indivíduo. É claro que podemos conceder tais possibilidades e confiança ao potencial cognitivo, bem como o fato de que teses esclarecidas articulam uma dimensão individual e social que devem funcionar em via de mão dupla, no sentido de mútua determinação. Isso pressupõe um indivíduo que racionaliza processos de determinação social, distancia-se e autodistancia-se deles de modo plausível - inclusive podendo se autotransformar -, de modo a poder dispor das racionalizações feitas, a fim de orientar novamente sua performance moral em um espaço social - sem perder a força normativa da possibilidade de transformação desse mesmo espaço ${ }^{12}$. A emancipação é intensificada na medida em que o indivíduo amplia seu horizonte de conhecimento, regulativa e

\footnotetext{
10 WESCHE, Reflexion, Therapie, Darstellung. Formen der Kritik, p. 204.

11 Talvez aqui fique mais clara minha suspeita a quaisquer telocracias que informam programas positivos à transformação, em detrimento dessa finalidade inflacionada, mas em proveito do aspecto processual da construção de juízos de caráter perfeccionista. Telocracias, digamos assim, enredam-se no imbróglio do limite da transformação, com chances maiores de autoilusão e perda do potencial normativo, além de poder flertar também com posições autoritárias. A dinâmica crítica e a maneira como lidamos com os desafios que envolvem qualquer transformação, a meu ver, lidam melhor com posições internas e externas na observação dos problemas, na medida em que assume com maior radicalidade a proposição segundo a qual nossos horizontes de perfecção devem se movimentar à medida em que nós mesmos nos movimentamos.

12 Em seu livro Die Möglichkeit der Normen: über eine Praxis jenseits von Moralität und Kausalität, Christoph Möllers emprega a expressão "Techiken der Selbstdistanzierung" como mecanismo que „define o cerne da prática normativa". Para Möller, essa técnica de distanciamento se exprime por meio da dinâmica "tomar distância do mundo, no mundo" (grifo meu). 0 distanciamento, por sua vez, também vem associado com a transformação como seu correlato normativo da tese esclarecida, em que "uma comunidade se distancia da própria realidade sob certas circunstâncias, mas não necessariamente, a fim de justamente transformar essa comunidade com algum sucesso, e isso igualmente sob seguidas circunstâncias." (MÖLLERS, Die Möglichkeit der Normen: über eine Praxis jenseits von Moralität und Kausalität, p. 14s.)
} 
recursivamente por meio de um espaço social que funciona em via de mão-dupla ${ }^{13}$. A equação equilibrada entre indivíduo e espaço social nas teses esclarecidas, em teoria, funcionaria no modelo de que transformações sociais são impossíveis sem transformação individual, assim como autotransformação sem reestruturação social é vazia e frustrante ${ }^{14}$.

Entretanto, nem tudo está disponível ao indivíduo para elaboração cognitiva, e nem os conflitos sociais do espaço em que alguém participa são suficientemente equilibrados para disposição e controle do indivíduo sobre eles. 0 resultado é ou a total subordinação do indivíduo ao contexto social, ou a pseudotransformação do indivíduo sem qualquer correlato de transformação social. 0 otimismo nas potencialidades cognitivas humanas para transformação, que tem nas teses esclarecidas a sua depositária fiel, perde a força normativa tão logo se minimiza o potencial dos conflitos internos, ou se torna vazia (talvez autoilusória?) quando também se depara com o abismo em relação aos mesmos conflitos. Teses esclarecidas, então, correm o risco de se converter em elitismo burguês ou intelectualismo vazio. Autotransformação sem um correlato social é frustrante e, nesse caso, a superestimação do indivíduo em relação aos conflitos internos desemboca justamente naquilo que a própria tese esclarecida pretende combater: a absorção e/ou subordinação do indivíduo ao contexto social. Subestimar os conflitos internos em proveito da superestimação individual exprime apenas o abismo entre a expectativa de transformação e a impotência ou vazio normativos. Nesse caso, os anseios de transformação por algo melhor pós-pandemia encontra seu claro obstáculo no limite da própria tese esclarecida. Se esse é o caso, então me parece que o anseio por algo melhor acaba figurando como verniz pequeno burguês.

As estruturas específicas dessa hipótese encontram sua demonstração no caso brasileiro. Desde a falência da tese do isolamento social em comunidades carentes, passando pelas narrativas perversas que, por um lado, exprimem o absoluto descaso e ausência de empatia com os corpos empilhados e, por outro lado, apelam ao fim do isolamento jogando o corpo marginalizado para se juntar aos já empilhados, até a estruturação necropolítica estatal que se acentuou no bolsonarismo por meio do gerenciamento do fosso que separa os que vão morrer e viver, cada uma dessas estruturas apenas reforça o limite da tese esclarecida, colocando em xeque nossos horizontes de expectativa. A lista do drama dos conflitos internos é extensa e sua facticidade nos confronta diariamente, com o adicional do crescente autoritarismo que germinou e tomou forma explícita nas relações interindividuais. É provável que algo diverso tome forma depois da pandemia, principalmente em se tratando das vantagens econômicas que estamos experimentando com o isolamento, como o fato de que o home office pode ser lucrativo às empresas, e a educação na forma EaD pode ser intensificada. Mesmo assim, trata-se ainda da reprodução das mesmas condições anteriores sob novas formas, indicando novamente que a própria transformação é um obstáculo para ela mesma.

\footnotetext{
13 Assim interpreto, p.ex., a relação entre nossa orientação no mundo cotidiano e a noção kantiana de "fremde Vernunft" (razão alheia). Segundo J. Simon, "Kant utiliza o conceito de uma 'razão alheia' [einer fremden Vernunft] numa dupla significação. Devemos testar as razões [Gründe] do próprio ter-por-verdadeiro [Fürwahrhaltens] em relação à 'razão alheia', mas por meio dela, contudo, tornar a 'pensar por si mesmo'. Ambas as orientações possuem entre si uma relação dialético-comunicativa." (SIMON, Die fremde Vernunft und die Sprache der Philosophie, p. 22) Em nossa performance moral, além disso, Kant já havia sugerido encontrar "muitos métodos heurísticos de pensar" (KANT, Was heißt: sich im Denken orientiren?, AA VIII, 133), e a meu ver a noção de fremde Vernunft é um recurso plausível para isso, quando entendida como mecanismo heurístico regulatório, por meio do qual podemos consolidar coerentemente nossos próprios juízos em âmbito público. A estreita conexão entre orientação e fremde Vernunft intensifica o potencial de autonomia, sobretudo quando associamos às três grandes máximas do Esclarecimento em geral: 1) pensar por si mesmo; 2) pensar colocandose no lugar de outra pessoa, e 3) pensar sempre de maneira coerente consigo mesmo. Se a primeira máxima é o lema do Esclarecimento, a segunda exerce a função da fremde Vernunft (imaginar se colocando no lugar de outro, ou seja, por meio de uma razão alheia), e a terceira intensifica os próprios juízos na medida em que intensifica ainda mais a autonomia, visto que a fremde Vernunft não é determinante de um juízo, mas apenas a lente de aumento por meio da qual temos nós próprios que operar a decisão (cf. KANT, Kritk der Urteilskraft §40, AA V, 295 e KANT, Logik, AA IX, 57). Sobre o tema da fremde Vernunft cf. STEGMAIER; SIMON. (Hg.). Fremde Vernunft: Zeichen und Interpretation IV.

${ }^{14}$ HEIT, Nietzsche als Kritiker und Denker der Transformation, p. 3.
} 
Qualquer anseio de transformação para algo melhor, em suma, pressupõe equacionar de maneira equilibrada as variáveis 'indivíduo' e 'conflito social', do contrário, permanecemos na esperança, e nada além!

As respostas ligeiras e superficiais normalmente tendem a ocupar o primeiro plano, sobretudo para fornecer um sentido ao sofrimento; mas enquanto tal, ainda fazem parte dos desdobramentos sobre o que significam ideais ascéticos, pois qualquer resposta é melhor do que nenhuma. É natural, então, que sejamos desejosos de uma transformação das nossas relações pessoais e culturais pós-pandemia, e claro, uma transformação para melhor. Sou cético em relação não ao anseio, mas à transformação. Seja pelo limite do significado da própria transformação, seja pelo limite das teses esclarecidas, ambas são imbróglios teóricos a serem debatidos em torno da vontade de transformação. Se essa investigação não aponta soluções, ao menos nos previne da autoilusão; se esses limites não são sistematizados, então estamos condenados às vãs esperanças.

Finalizo brevemente com uma indicação em torno da urgência de um programa genealógico da cultura brasileira e sua relação com a práxis crítica, no interior do debate filosófico. Esse debate, inclusive, não poderia prescindir da interlocução com outras áreas que há muito já se debruçaram sobre o tema, como história, ciências sociais, a literatura e mesmo a antropologia. Em termos filosóficos, trata-se menos da formulação de um programa positivo ao drama dos nossos conflitos internos - em função do limite que a noção mesma de transformação impõe para si - e muito mais do programa filosófico que conjuga crítica e genealogia, no sentido não apenas de sistematizar as principais categorias por meio das quais interpretamos nossa cultura, mas também de colocar a pergunta sobre o que fizemos e ainda fazemos em termos políticos da sistematização dessas categorias, a serviço de quê/quem elas estão, ou ainda de que maneira suas características e mutações no interior das nossas relações podem se vincular a um horizonte maior de juízos práticos de caráter perfeccionista ${ }^{15}$. A crítica é impulso à transformação, na medida em que um programa genealógico insere o interlocutor no mesmo processo em que é criticado, abrindo margem de manobra para que se reconheça na própria crítica, desvelando comprometimentos e forçando posteriores responsabilizações. Espera-se, claro, um desdobramento terapêutico desse exercício críticogenealógico, no sentido de um plausível apelo à autotransformação. A meu ver, nossos autores clássicos que investigaram a formação cultural brasileira e sua respectiva fortuna crítica podem fornecer plausíveis chaves de leitura conceituais na tentativa de reequilibrar as variáveis 'indivíduo' e 'conflitos internos'. Correndo o risco de cometer alguma injustiça em deixar alguma chave de leitura de fora, reconheçamos que da reflexão da herança colonial escravagista como chaga viva e não resolvida entre nós (G. Freyre), passando pelas relações patrimonialistas e o tipo homem cordial (Sérgio Buarque), a estruturação de relações dialéticas na nossa cultura, seja como dialética da colonização (A. Bosi), seja como dialética da dependência (R. M. Marini), as possibilidades de transformações sociais ou revolução social com o respectivo questionamento da suposta democracia racial (F. Fernandes), até os debates mais atuais em torno de uma elite do atraso e o uso político do argumento da corrupção (Jessé de Souza), além, é claro, do material fecundo da literatura brasileira, todos eles são matéria prima essencial para compreensão da gênese da nossa cultura e autocompreensão de nós mesmos por meio do desvelamento dos nossos principais comprometimentos culturais. Cada uma dessas chaves de leitura não compete entre si, mas se complementam em torno de um quadro maior da gênese das nossas determinações culturais. Um programa genealógico e crítico, não pretende, nesse caso, indicar formulações positivas para soluções, mas enfatizar que a crítica deve mobilizar continuamente os esforços de desvelamento e problematização das nossas determinações: ela é menos propositiva, e mais ferramenta de desvelamento. Um programa que conjuga genealogia e crítica pode prescindir das telocracias, em proveito da

15 Sobre isso, cf. MENKE, C. Genealogie und Kritik: zwei Formen ethischer Moralbefragung, e SAAR, M. Genealogie als Kritik. 
dinâmica processual das nossas formulações, reestruturações e reorientação da vida prática ${ }^{16}$. Também a filosofia no Brasil precisa cultivar seu próprio jardim.

\section{Agradecimentos}

Agradeço à Tássyla pelas interlocuções diárias sobre o programa genealógico e crítico da cultura brasileira, e aos amigos Douglas, Marcio e Igor pelos impulsos, provocações e fecundos debates que forneceram o pano de fundo a esse texto.

\section{Referências}

HEIT, H.; THORGEIRSDOTTIR, S. (Hrgs). Nietzsche als Kritiker und Denker der Transformation. (Nietzsche Heute), Band 6, Berlin/Boston: Walter de Gruyter, 2016.

JAEGER, Werner. Paideia: a formação do homem grego. Trad. Artur M. Parreira. São Paulo: Martins Fontes, 2013.

KANT, I. Kants Gesammelte Schriften. 29 Band. Berlin: Ak Berlin, 1902.

KANT, I. Werke in zehn Bänden. Darmstadt: Wissenchaftliche Buchgesellchaft, 1983.

KOSELLECK, R. Krisis. In: RITTER, J. (Hrsg.), Historisches Wörterbuch der Philosophie. Band 4: I-K. Basel/Stuttgart: Schwabe \& Co. Verlag, 1972.

MENKE, C. Genealogie und Kritik: zwei Formen ethischer Moralbefragung. In: Nietzscheforschung, vol. 5-6 (1998), pp. 209-226.

MÖLLERS, C. Die Möglichkeit der Normen: über eine Praxis jenseits von Moralität und Kausalität. Berlin: Suhrkamp Verlag, 2018.

NIETZSCHE, F. Sämtliche Werke. Kritische Studienausgabe in 15 Bänden. (KSA) Hrsg. Giorgio Colli und Mazzino Montinari. Berlin/New York: DTV \& Walter de Gruyter, 1999.

SAAR, M. Jenseits der Revolte - Nietzsche als Denker und Kritiker sozialer Transformation. In: HEIT, H.; THORGEIRSDOTTIR, S. (Hrgs). Nietzsche als Kritiker und Denker der Transformation. (Nietzsche Heute), Band 6, Berlin/Boston: Walter de Gruyter, 2016. pp. 93-111.

SAAR, M. Genealogie als Kritik. Frankfurt/New York: Campus Verlag, 2007.

SOOVÄLI, J. Entscheidung als Häresie. In: Studia Philosophica Estonica, 7.1 (2014), pp. 58-83.

SIMON, J. Die fremde Vernunft und die Sprache der Philosophie. Berlin/New York: Walter de Gruyter, 2003.

STEGMAIER, W.; SIMON, J. (Hg.). Fremde Vernunft: Zeichen und Interpretation IV. Frankfurt/M: Suhrkamp, 1998.

VIESENTEINER, Jorge L. Considerações sobre juízos práticos perfeccionistas em Nietzsche. (No prelo)

WESCHE, T. Reflexion, Therapie, Darstellung. Formen der Kritik. In: Was ist Kritik. 5. Auf. Frankfurt am Main: Suhrkamp, 2019. pp. 193-220.

16 Da pesquisa de pós-doutorado atual sobre juízos práticos perfeccionistas, venho escrevendo sobre os desdobramentos dessa noção em três âmbitos principais de investigação: na psicologia, na educação e no experimento de uma filosofia da cultura com as chaves de leitura elaboradas no debate brasileiro. 